\title{
DETECCIÓN MOLECULAR DE SECUENCIAS DE ADN TRANSGÉNICO EN ALIMENTOS DE CONSUMO HUMANO Y ANIMAL EN COSTA RICA
}

\author{
Paula Carvajal*, Hilary Ureña*, Josué Umaña**, Carolina Sancho*, Frank Solano***, \\ Mailén Arleo ${ }^{* * * *}$, Claudio Martínez $z^{* * * *}$, Rodolfo Umaña $a^{1 / *}$ \\ Palabras clave: OGM; trazabilidad; PCR punto final; maíz; soya; transgénicos. \\ Keywords: GMO; traceability; end-point PCR; maize; soybean; transgenics.
}

Recibido: $25 / 04 / 16$

RESUMEN

Desde la introducción de los cultivos genéticamente modificados (GM), ha habido un crecimiento continuo en adopción de la tecnología y en la comercialización de alimentos y piensos derivados de cultivos GM alrededor del mundo. Gobiernos y organizaciones han desarrollado métodos para detectar rápidamente y con alto rendimiento los alimentos y piensos derivados de cultivos GM, y así verificar el cumplimiento de las regulaciones dirigidas a proveer información al consumidor. El objetivo de este estudio fue determinar la presencia de secuencias de ADN derivadas de maíz y soya GM, en una gama de piensos y alimentos, sin procesar y procesados, comercializados en Costa Rica, un mercado sin regulaciones que indiquen contenido transgénico en el etiquetado. Se empleó el método cualitativo estándar, de reacción en cadena de la polimerasa (PCR) en punto final, para la detección de material GM a partir las regiones comunes del promotor $35 S$ y el terminador NOS, seguido de la detección específica de los eventos de maíz Bt11, MON810, GA21 y NK603, así como el evento de

1 Autor para correspondencia. Correo electrónico: rodolfo.umana.castro@una.cr

* Universidad Nacional, Laboratorio de Análisis Genómico, Costa Rica.

** Universidad Nacional, Escuela de Ciencias Agrarias, Costa Rica.
Aceptado: 06/12/16

\section{ABSTRACT}

Molecular detection of transgenic DNA sequences in human food and animal feed in Costa Rica. Since the introduction of genetically modified (GM) crops, there has been a continuous growth in adoption of the technology and in commercialization of food and feed products derived from GM crops worldwide. Governments and organizations have developed methods for rapid and high throughput screening of GM-derived foods and feeds, to verify compliance with labelling regulations aimed at providing information to consumers. The objective of this study was to determine the presence of DNA sequences, derived from GM maize and soy, in a range of unprocessed and processed foods and feeds commercialized in Costa Rica, a market without regulations to indicate transgenic content in the labelling. The standard end-point qualitative method of polymerase chain reaction (PCR) was used for detection of GM material, the common regions of the $35 \mathrm{~S}$ promoter and the NOS terminator, followed by the specific detection of maize Bt11,

\footnotetext{
*** Universidad Nacional, Laboratorio de Biotecnología de Plantas, Costa Rica.

**** Universidad de la República, Facultad de Ciencias, LaTraMA-Laboratorio de Trazabilidad Molecular Alimentaria, Uruguay.
} 
soya GTS 40-3-2, en una selección de alimentos y piensos disponibles en Costa Rica. Los resultados generales de la detección de secuencias derivadas de cultivos GM fueron: $86 \%$ para el promotor $35 S, 72 \%$ para el terminador NOS y $40 \%$ para los eventos identificados. Los eventos más frecuentemente detectados fueron MON810, NK603 y Bt11. Los resultados demostraron que existen alimentos y piensos derivados de cultivos GM en el mercado local y que la significancia y viabilidad del etiquetado de los productos, para proveer información a los consumidores, debería ser abordado por las autoridades competentes. Sin embargo, todavía falta realizar estudios cuantitativos en los análisis de rutina, para detectar si el límite de material GM, establecido por la regulación sobre alimentos y piensos GM de la Unión Europea, se ha extralimitado.

\section{INTRODUCCIÓN}

El cultivo mundial de plantas genéticamente modificadas (ha registrado un incremento sostenido. El área global sembrada con cultivos transgénicos aumentó de 1.7 millones de hectáreas en 1996 a 44.2 millones de hectáreas en el 2000, mientras que para el 2015; según el Servicio Internacional para la Adquisición de Aplicaciones Agrobiotecnológicas (ISAAA), 179,7 millones de hectáreas cultivadas eran cultivos biotecnológicos (Schaper y Parada 2001).

En América, Estados Unidos es el país que más contribuye en cultivos de este tipo, ya que ha presentado el mayor incremento anual absoluto del mundo en la siembra de cultivos GM (70,9 mill ha), seguido de Brasil (44,2 mill ha), Argentina (24,5 mill ha) y Canadá (11,0 mill ha) (James 2015). En el 2012, en México fue aprobada la siembra del evento MON-04032-6
MON810, GA21, and NK603 events, as well as the soybean GTS 40-3-2 event, in a selection of foods and feeds available in Costa Rica. The overall results of the GM crops screening were: $86 \%$ for the $35 \mathrm{~S}$ promoter, $72 \%$ for NOS terminator and $40 \%$ for identified events. The most frequently detected events were MON810, NK603 and Bt11. The results showed that GM crops-derived foods and feeds are found in the local market, and that the significance and viability of product labelling, to provide information to consumers, should be addressed by competent authorities. However, quantitative studies on the routine analyses are still needed, to detect if the threshold of GM material, set by the European Union GM food and feed regulation, has been exceeded.

de soya transgénica por parte de la Secretaría de Agricultura, Ganadería, Desarrollo Rural, Pesca y Alimentación (SAGARPA), sin embargo, durante el 2014 se emitió una orden judicial para prohibir la liberación comercial del evento, en 7 estados de la República Mexicana (Claver 2013, González 2014). Además, en el 2012, SAGARPA concedió el permiso de liberación en fase piloto y experimental de maíz transgénico a empresas transnacionales. Sin embargo, en el 2013 se suspendió la liberación del maíz como medida precautoria, hasta que se determine una resolución jurídica (González 2014).

En Centroamérica, países como Guatemala, El Salvador, Honduras y Nicaragua se han dedicado al cultivo de maíz GM (MoralesEstupiñán 2001). En Guatemala la introducción de OGM ha ocurrido sin regulaciones, por lo que se ha generado un debate nacional sobre el cultivo de éstos (Landaverry 2014). En el Salvador, el 
tratado de libre comercio ha permitido el ingreso continuo de alimentos genéticamente modificados producidos en Estados Unidos (Franco-Ortíz et al. 2014). En Nicaragua, los eventos transgénicos autorizados para el cultivo son Bt176, Bt11, MON863, MON810, GA21 y NK603, entre otros (Álvarez et al. 2012).

En Costa Rica, actualmente, los cultivos transgénicos han sido autorizados únicamente para el incremento de semillas de algodón y soya, para investigaciones de tipo experimental en maíz, piña, banano, plátano, arroz y tiquizque (James 2015). Por otro lado, el $91 \%$ de los municipios del país se han declarado libres de transgénicos (Pacheco y García 2014). Según datos del Servicio Fitosanitario del Estado, en Costa Rica, desde 1991 hasta el 2016 se registran 11687,43 ha de superficie plantada con OGM, entre los cuales destacan algodón con 10686,66 ha, soya 905,48 ha, arroz 1,8 ha, banano 19,1 ha y piña con 68,47 ha (MAG 2016a).

En Costa Rica, la Dirección del Servicio Fitosanitario del Estado (SFE) del Ministerio de Agricultura y Ganadería (MAG), es el ente encargado del control y monitoreo sobre los organismos transgénicos en el país, al otorgar o negar las solicitudes de siembra comercial o de investigación que se deseen ejecutar con organismos transgénicos. Cabe destacar que a la Dirección del SFE no le corresponde la evaluación de los productos derivados a partir de estos organismos. La Dirección del SFE es asesorada principalmente por la Comisión Técnica Nacional de Bioseguridad (CTNBio), la cual ha jugado un papel importante en los procesos de introducción de eventos transgénicos en el agro del país (Pacheco y García 2014), al recomendar la concesión de permisos a compañías subsidiarias de corporaciones transnacionales para la reproducción de semillas e investigación (MAG 2016b).

Por otro lado, en cuanto a las regulaciones que indiquen contenido transgénico en el etiquetado de productos envasados en Costa Rica, la Secretaría Técnica del Comité Nacional del Codex Alimentarius en Costa Rica procedió a homologar la Norma general del Codex para el
Etiquetado de los Alimentos Preenvasados Codex Stan 1-1985 (Rev. 1-1991), mediante la adopción de los reglamentos técnicos RTCR 100:1997 y RTCA 67.01.07:10. Sin embargo, ni en la Norma ni en estos reglamentos se aborda el etiquetado de alimentos derivados de la biotecnología moderna. Por lo anterior, el Codex Alimentarius Costa Rica solo dispone de los Principios para el Análisis de Riesgos de Alimentos derivados de la Biotecnología Moderna (CAC/GL 44-2003) donde se indica que "las medidas de gestión de riesgos pueden incluir, según sea apropiado, el etiquetado de alimentos, las condiciones para aprobar su comercialización y la vigilancia tras la puesta en el mercado". Asimismo, el Reglamento a la Ley de Protección Fitosanitaria N. 26921-MAG indica en su artículo 131 que "para introducir y/o comercializar en Costa Rica productos vegetales u otros organismos modificados genéticamente de uso en la agricultura, deberán ser identificados como tales en una etiqueta en donde el consumidor reconozca las características del producto", lo que excluye a los alimentos preenvasados derivados de la biotecnología moderna.

La trazabilidad alimentaria en Costa Rica no es eficiente como lo indica García (2007), ya que tanto los importadores de alimentos como el Estado no ven relevante lo indicado en los artículos 46 y 48 de la Ley de Biodiversidad (Costa Rica 1998), en cuanto a lo establecido en materia de importación de OGM, tal como en el caso de semillas y granos para consumo, los cuales podrían ser viables en su germinación luego de su importación y transporte dentro del país. La detección de OGM en alimentos puede realizarse por múltiples técnicas de biología molecular, entre la más usadas esta la amplificación de las secuencias de ADN transgénicas mediante PCR punto final (cualitativa) y PCR tiempo real (cuantitativa, qPCR) (Hurst et al. 1999, Querci et al. 2009). El Centro Común de Investigación de la Comisión Europea (European Commission's Joint Research Centre-JRC) avala 118 métodos de PCR (cualitativos y cuantitativos), los cuales se encuentran descritos en el Compendio de Métodos de Referencia para el análisis de OGM, 
"Compendium of reference Methods for GMO analysis" (Bonfini et al. 2012).

El análisis por PCR punto final permite hallar e identificar remanentes de ADN derivado de OGM, en alimentos procesados, ya sea por la localización de regiones promotoras y/o terminadoras en la arquitectura del transgén, o la identificación de genes que le confieren características específicas a un evento de transformación específico; que se caracteriza por ser una variante vegetal determinada en cuanto a la integración del o los transgenes en la planta (sitio de integración en el genoma de la misma, número de copias del o los transgenes, nivel de expresión de la o las proteínas de interés, etc.). La técnica de PCR posee dificultades a nivel molecular respecto al aislamiento de trazas de ADN debido a diversos factores que contribuyen a la degradación de éste, tales como procesos de cocción, cambios drásticos de $\mathrm{pH}$, actividad de nucleasas y presencia de agentes químicos que pueden degradar la estructura nucleotídica (Holst-Jensen et al. 2003). Asimismo, los compuestos presentes en los alimentos procesados como las proteínas, grasas, polisacáridos, polifenoles, extractos de cacao y azúcar caramelizado pueden inhibir la ADN polimerasa, y disminuir la eficiencia en la detección del OGM por PCR (Ahmed 2002). Por lo tanto, el método de extracción y purificación de ADN total de los alimentos procesados, es un paso crítico para la detección de las secuencias de ADN transgénico por medio de PCR. El objetivo de este estudio fue evidenciar la presencia o ausencia de trazas de ADN de maíz y soya GM en alimentos procesados, granos y piensos compuestos disponibles en el mercado costarricense, por medio de la detección de secuencias específicas utilizando la técnica molecular cualitativa de PCR en tiempo final.

\section{MATERIALES Y MÉTODOS}

\section{Obtención de muestras}

Se analizaron 36 alimentos sólidos de consumo humano y animal, con o sin ingredientes de maíz ó soya aparente en su fabricación, de venta en establecimientos comerciales de las provincias de Heredia, Cartago y San José. Entre los alimentos que fueron analizados están tortillas y chips tostados de maíz, chips de papa tostada, harinas de maíz, cereales de maíz azucarados, magdalenas dulces, embutidos, concentrados de consumo animal y granos de maíz para molienda o siembra, tal como se muestra en resultados más adelante.

\section{Extracción y cuantificación del ADN total de matrices complejas}

Previo a la extracción de ADN se eliminó el exceso de condimento en polvo, azúcar y otros aditivos que contenían los alimentos procesados en su superficie. Además, se limpiaron los instrumentos con hipoclorito de sodio comercial al 10\% para evitar la contaminación entre muestras y se utilizaron guantes de nitrilo (sin almidón de maíz) en el proceso de manipulación. La extracción de ADN total se realizó según el protocolo de Doyle y Doyle (1987) con algunas modificaciones. Las muestras fueron maceradas en un disruptor mecánico (MM400, Retsch, Haan, Alemania) con 2 balines de acero inoxidable de $15 \mathrm{~mm}$. Se tomó $100 \mathrm{mg}$ del material pulverizado y se homogenizó en solución de extracción CTAB (Tris- $\mathrm{HCl}$ $100 \mathrm{mM}$, pH 8,0; EDTA 50 mM, pH 8,0; $\mathrm{NaCl}$ $1,4 \mathrm{M}$; bromuro de cetiltrimetilamonio (CTAB) 2\%; $\beta$-mercaptoetanol $140 \mathrm{mM}$ ). Posteriormente, se adicionó una solución de cloroformo:octanol (24:1) y 0,8 volúmenes de isopropanol frío para precipitar el ADN total. La concentración e integridad de los ácidos nucleicos recuperados se determinó en un espectrofotómetro (NanoDrop 2000, Thermo Scientific, Waltham, MA, USA) y el perfil de ADN total se visualizó en geles de agarosa al 1,0\% en solución tris/borato/EDTA (TBE) $1 \mathrm{X}$.

\section{Detección de secuencias transgénicas derivadas de OGM e identificación de eventos específicos mediante PCR de punto final}

Las muestras de ADN fueron analizadas con cebadores descritos en el Compendio de 
Métodos de Referencia para el análisis de OGM del Centro Común de Investigación (JRC) de la Comisión Europea (Van den Eede et al. 2010). La presencia de secuencias de maíz y soya en los alimentos fue confirmada mediante la amplificación de un fragmento de los genes endógenos de una proteína de la familia A del grupo de alta movilidad del maíz, y de la proteína lectina de la soya, mediante los cebadores $h m g A$ y Lel, respectivamente. Se determinó la presencia de secuencias derivadas de OGM en las muestras al ampliar una región de ADN del promotor 35S del virus del mosaico de la coliflor $(\mathrm{CaMV})$ y del terminador del gen nopalina sintasa ( $t$-Nos) de Agrobacterium tumefaciens, utilizados en la mayoría de los cultivos GM (Barbau-Piednoir et al. 2010 y Holden et al. 2010). Además, se identificó la presencia de secuencias de ADN de los eventos transgénicos específicos de maíz MON810 -mediante la amplificación de la región de unión entre el intron 1 del gen $h s p 70$ de maíz y el gen sintético de la proteína cristalina insecticida $C r y l A b$ de Bacillus thuringiensis (cebadores IVS-HSP-F/ CryIA(b)-R)-, el evento Bt11 mediante la amplificación de la región fronteriza de integración (IBR, por sus siglas en inglés) en el extremo 3'entre el inserto en el evento Bt11 y el genoma del maíz (Bt11-INS-F/3'JUNC-R), el evento NK603 por medio de la amplificación de la $I B R$ en el extremo 3' entre el inserto del evento $N K 603$ y el genoma del maíz (cebadores NK603-INS-F/3'JUNC-R), y el evento GA21 al amplificar la IBR en el extremo 5' entre el inserto del evento GA21 y el genoma del maíz (cebadores GA21-5'JUNC-F/INS-R). También se identificó el evento GTS 40-3-2 de soya por medio de la amplificación de la región de unión entre el promotor 35S y la secuencia del péptido señal de tránsito al cloroplasto $(C T P$, por sus siglas en inglés) del gen epsps de Petunia hybrida (cebadores P-35Ssoy-F/ CTP4-R) (Cuadro 1). Como controles positivos se utilizó material biológico proporcionado por el Laboratorio de Trazabilidad Molecular Alimentaria (LaTRAMA), FCIEN, UdelaR, Uruguay (Arleo 2015) obtenido a partir de Materiales de Referencia Certificados (MRC) del Institute for Reference Materials and Measurements (IRMM, Bélgica). Por otra parte, como control negativo de transgenicidad, se empleó maíz orgánico certificado, cultivado y comercializado en Costa Rica. 


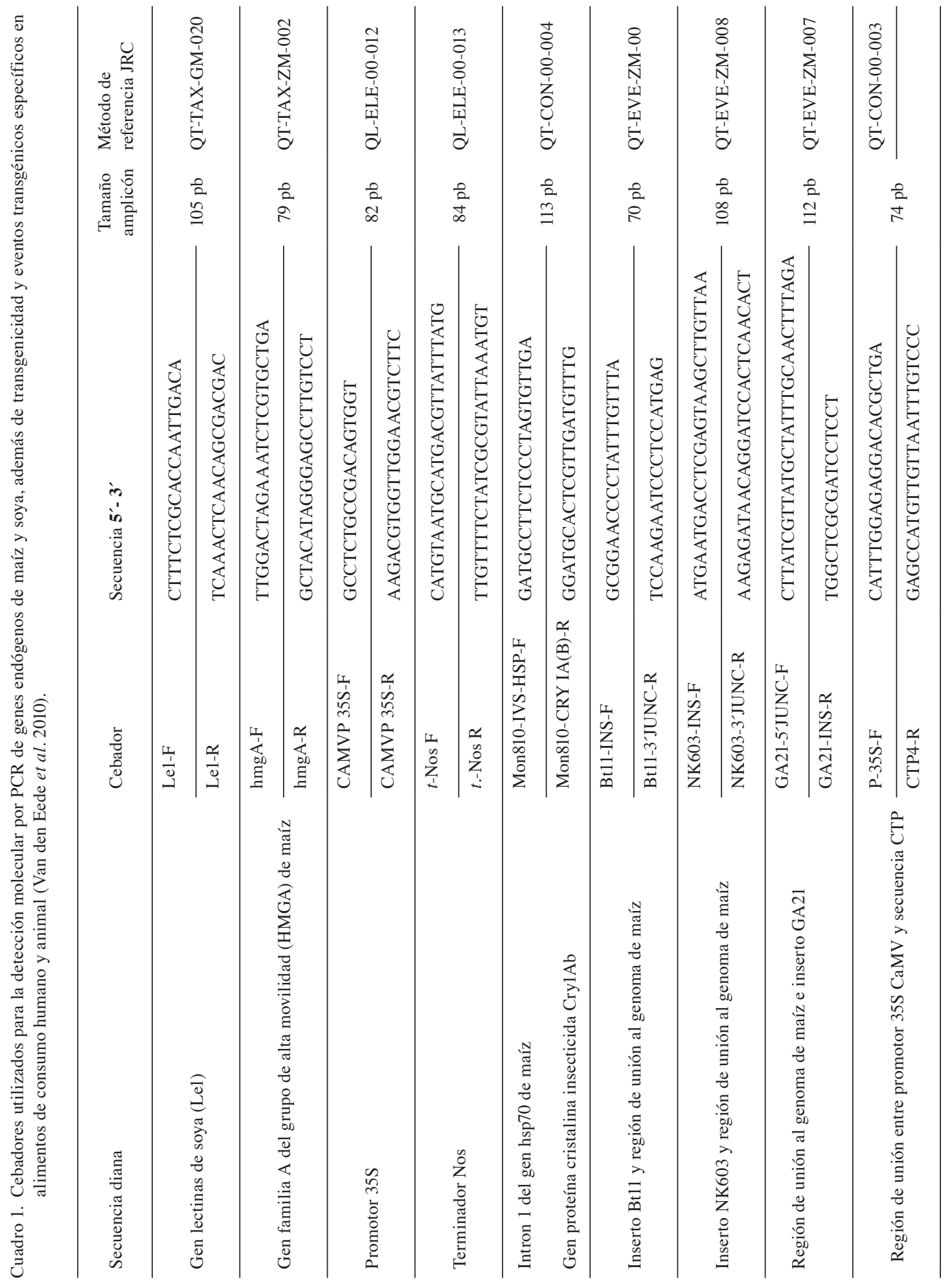


La amplificación por PCR fue diseñada con un Master Mix $(0,2 \mathrm{mM}$ de cada dNTP, $0,025 \mathrm{U} . \mu \mathrm{l}^{-1} \mathrm{ADN}$ polimerasa, tampón de reacción y $2 \mathrm{mM} \mathrm{MgCl}_{2}$, Thermo Scientific), $0,4 \mu \mathrm{M}$ de cada uno de los cebadores y 100-150 ng de ADN total. La reacción de amplificación se llevó a cabo en un termociclador (Proflex PCR System; Applied Biosystems, Life Technologies, EE.UU.) bajo las siguientes condiciones: 4 min a $94^{\circ} \mathrm{C}$, seguida de 33 ciclos de $30 \mathrm{~s} \mathrm{a}$ $94^{\circ} \mathrm{C}, 30 \mathrm{~s}$ a $60^{\circ} \mathrm{C}$ (temperatura de hibridación optimizada para todos los cebadores utilizados en este estudio) y 30 segundos a $72^{\circ} \mathrm{C}$, seguido de una extensión final a $72^{\circ} \mathrm{C}$ por $7 \mathrm{~min}$. Para visualizar los productos de PCR se realizó una electroforesis en gel de agarosa al $3 \%$ en TBE $1 \mathrm{X}$, con un tiempo de movilidad electroforética de $100 \mathrm{~min}$ a $80 \mathrm{~V}$. Los productos fueron teñidos con GelRed (Biotium, Hayward, CA, EE. UU) y digitalizado en un fotodocumentador (BioDocIt,UVP, Upland, CA, EE.UU.). El tamaño aproximado de los amplicones PCR se determinó mediante secuenciación automatizada como se describe más adelante.

\section{Purificación de los productos de PCR y secuenciación}

Algunos amplicones representativos, obtenidos por el análisis PCR de punto final para el terminador de la nopalina sintasa ( $t$-Nos) y para eventos específicos en maíz y soya (MON810, GA21, NK603 y GTS 40-3-2) fueron purificados enzimáticamente mediante Exonucleasa I (20U. $\left.\mu 1^{-1}\right)$ y fosfatasa alcalina termosensible FastAp (Thermo Scientific) (1U. $\left.\mu \mathrm{l}^{-1}\right)$, según las instrucciones del fabricante. Por otro lado, se utilizó un protocolo alternativo de limpieza y purificación de productos de PCR mediante precipitación con etanol 95\% y acetato de sodio 3M. Los productos de PCR purificados fueron secuenciados en ambas direcciones en un analizador genético multicapilar (3130, Applied Biosystems) en el Laboratorio de Análisis Genómico (LAGEN) de la Escuela de Ciencias Biológicas de la UNA y empleando una química de reacción de tipo Sanger (BigDye Terminator ${ }^{\mathrm{TM}}$ V3.1,
Applied Biosystems). Las secuencias recuperadas fueron editadas con el programa bioinformático Geneious R9 (Biomatters Ltd. Nueva Zelanda) y analizadas utilizando la herramienta básica de búsqueda local de similitud (BLASTn, por sus siglas en inglés, Altschul et al. 1990) de la base de datos NCBI (Johnson et al. 2008) mediante parámetros por defecto.

\section{RESULTADOS Y DISCUSIÓN}

\section{Extracciones de ADN e integridad del ADN total}

La concentración del ADN total obtenido de las muestras de alimentos procesados, derivado del análisis espectrofotométrico, se situó entre los 72,33 ng. $\mu l^{-1}$ y 3893,47 ng. $\mu l^{-1}$. De acuerdo con la relación $\mathrm{Abs}_{260 \mathrm{~nm}} / 280 \mathrm{~nm}$, las muestras presentaron valores cercanos al óptimo de pureza (entre 1,6 y 1,8), a excepción de las muestras M-09, M-41, M-42, M-43 M-56 que mostraron la presencia de proteínas, con valores menores a 1,8 (Gallagher 2001); las muestras M-18, M-20 y M-27 contenían trazas de solventes orgánicos como el cloroformo, el cual fue utilizado en el proceso de la extracción de ADN (dato no mostrado). Por otra parte, la relación $\mathrm{Abs}_{260 \mathrm{~nm}} / 230 \mathrm{~nm}$ (valor óptimo entre $2,0-2,2)$ demostró que las muestras presentaban moléculas copurificadas como sales, carbohidratos, péptidos, fenoles o compuestos aromáticos, a excepción de las muestras M-46 y M-47 (dato no mostrado). Estos resultados son esperables, ya que muchas de las muestras provienen de matrices complejas derivadas de alimentos procesados. La obtención de bajos coeficientes 260/280 también han sido reportados en otros estudios que realizan extracciones de alimentos procesados, donde se han obtenido valores de 1,17; 0,99 y 1,33 para muestras como tofu, harina de soya y lecitina, respectivamente (Zimmermann et al. 1998) y de 0,$96 ; 0,99 ; 0,95$ y 0,98 para muestras de alimentos procesados de soya, maíz, papa y trigo, respectivamente (Pauli et al. 2000). De manera similar, en otros estudios ha sido imposible obtener ADN de buena calidad en alimentos 
altamente procesados como cereales, siropes y piensos (Margarit et al. 2006). Sin embargo, ninguna de las reacciones de PCR punto final dirigidas a genes endógenos (HMGA de maíz y Lelde soya) o a regiones del ADN que evidencian la presencia secuencias derivadas de OGM $(C a M V-35 S)$ fueron inhibidas debido a estas impurezas. La calidad del ADN obtenido puede ser mayor si se utiliza un conjunto de piezas comerciales especializadas en recuperar trazas de ADN de alimentos, sin embargo, estos resultan menos eficientes en cuanto a la concentración de ácidos nucleicos totales en la muestra y además tiene asociado un costo mayor por muestra (Zimmermann et al. 1998).

\section{Detección de genes endógenos de maíz y soya}

Los análisis de detección molecular del gen endógeno del maíz HMGA mostraron que 28 de los 30 alimentos analizados (93\%) contenían secuencias específicas de maíz, de los cuales 3 no reportaban en su descripción la utilización de maíz o sus derivados como parte de sus ingredientes (Cuadro 2, muestras M-41, M-42 y M-63). En todas las muestras de maíz o con derivados de este, se pudo identificar la presencia del gen $H M G A$, con un tamaño aproximado de $79 \mathrm{pb}$, salvo en la muestra M-20 donde no se obtuvo un amplicón. Por otra parte, se detectó la presencia de un fragmento del gen que codifica la lectina de soya (Lel) en el 46\% (14/30) de las muestras analizadas, con un tamaño molecular de 105pb (Figura 1A), a pesar de que el $85 \%(12 / 14)$ de las muestras positivas no son productos fabricados con soya como ingrediente. Sin embargo, estos alimentos podrían contener productos derivados de soya como la lecitina de soya, que es utilizada como agente surfactante, el fabricante podría no describir realmente los ingredientes debido a que se usa en muy poca proporción, o el alimento podría ser procesado en una fábrica donde también se manipulan otros productos que contienen soya (Cuadro 2, M-04, M-07, M-21, M-29, M-41, M-43, M-46, M-47, entre otras). 


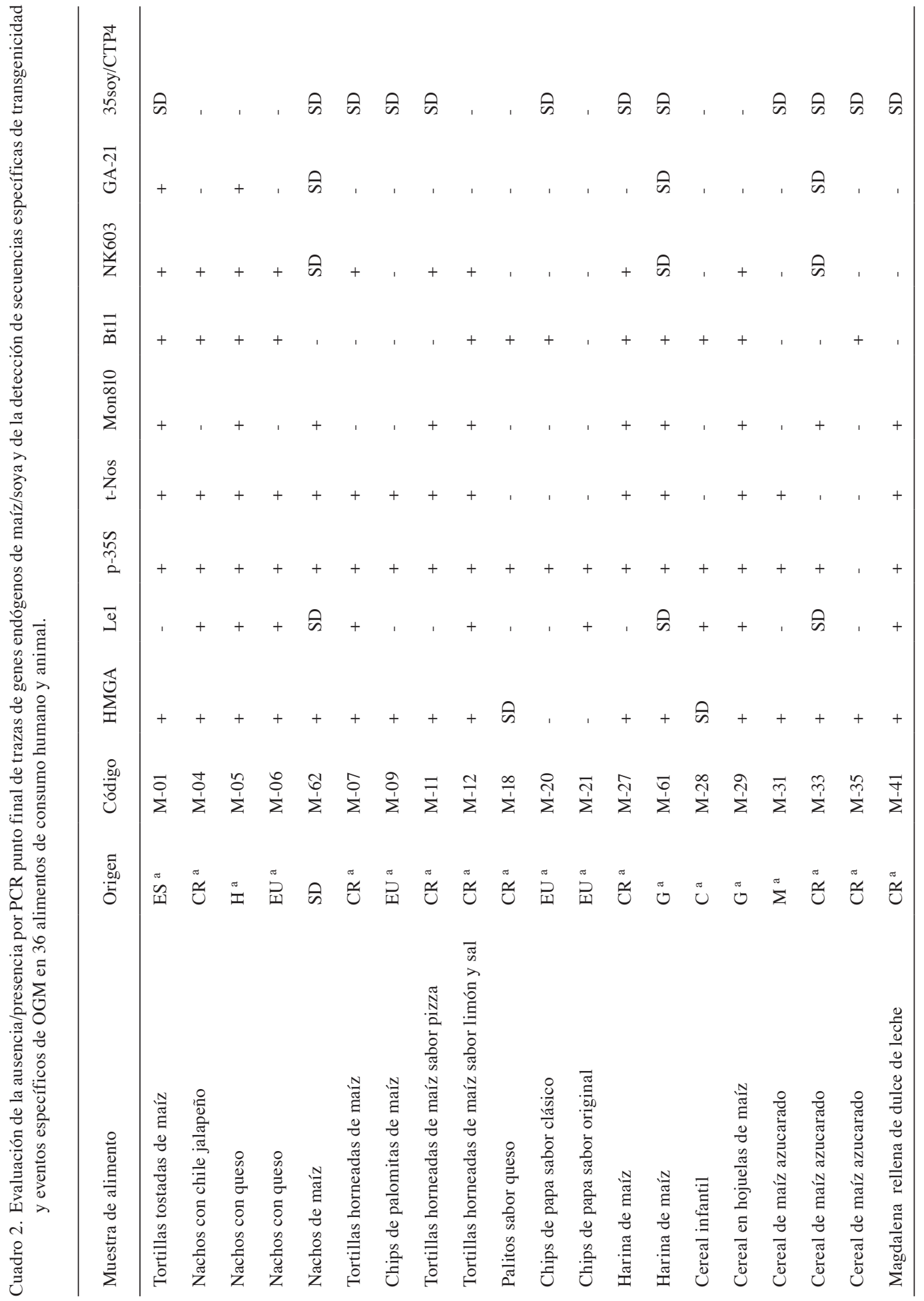




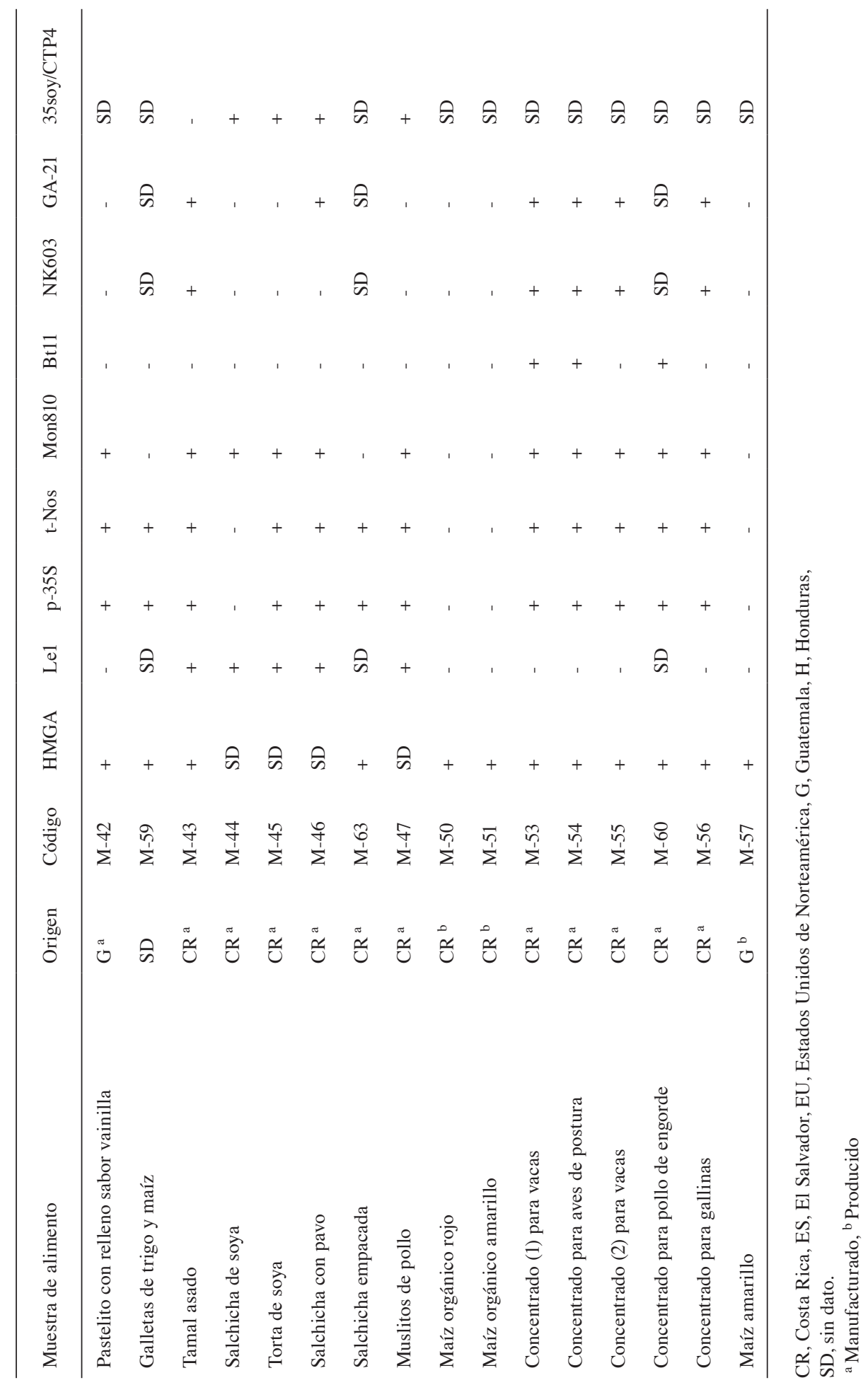

Agronomía Costarricense 41(1): 53-68. ISSN:0377-9424 / 2017 


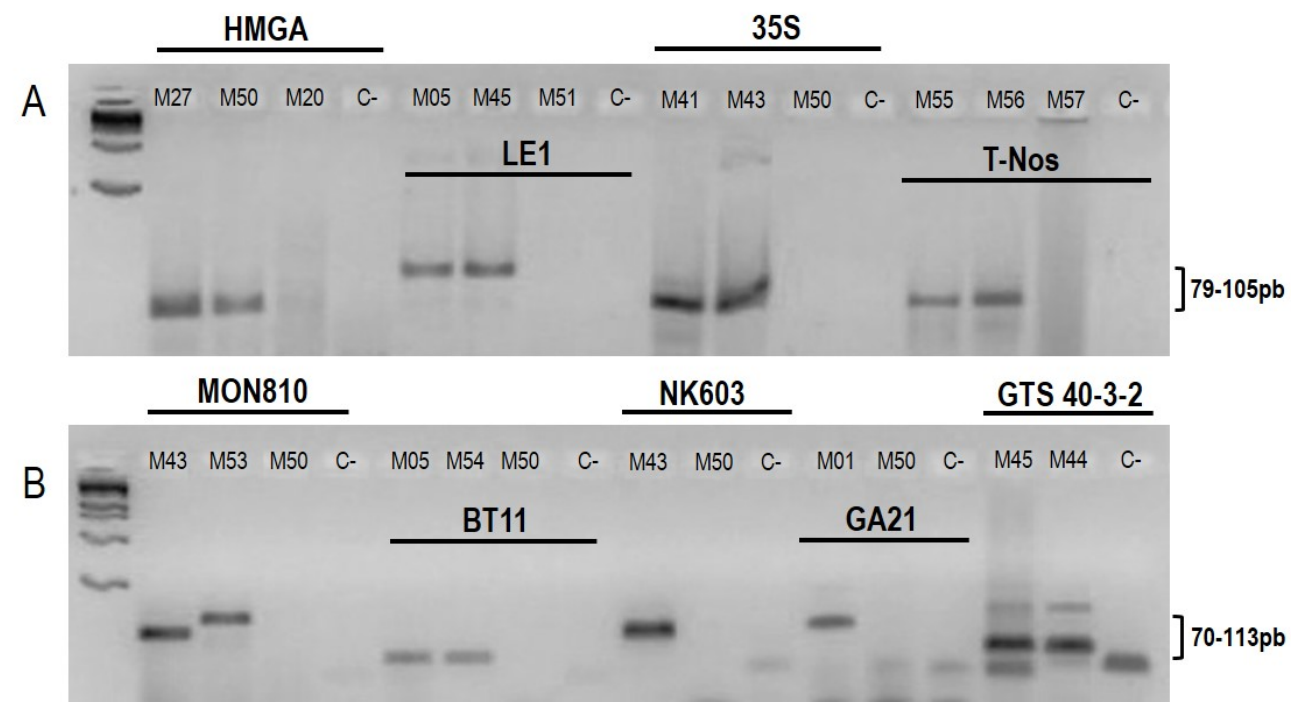

\begin{abstract}
A) Productos de amplificación de genes endógenos de maíz (HMGA), soya (Le1) y ensayos de detección de OGM (35S y t-nos) en un rango de peso molecular entre los 79 pb y $105 \mathrm{pb}$.

B) Productos de amplificación de eventos transgénicos específicos de maíz (MON810, Bt11, NK603, GA21) y el evento GTS 40-3-2 en soya con un rango de peso molecular entre 70pb a 113pb. Los códigos en los carriles corresponden a las muestras del Cuadro 2. Los controles negativos (C-) son controles de reacción PCR sin ADN. Escalera de peso molecular GeneRuler $1 \mathrm{~Kb}$ (Thermo Scientific).
\end{abstract}

Fig. 1. Productos de PCR visualizados mediante electroforesis en gel de agarosa.

\section{Detección de transgénesis e identificación de eventos específicos}

El ensayo de detección de OGM, validado internacionalmente, y basado en la amplificación de las secuencias génicas del promotor $C a M V$ $35 S$ y el terminador $t$-Nos, presentes en las construcciones de la mayoría de los eventos aprobados para su comercialización internacional, demostró que un $86 \%$ de las muestras de alimentos procesados analizadas (31/36) contiene secuencias transgénicas. En todas ellas se detectó un fragmento del promotor $35 \mathrm{~S}$ con un amplicón observable de aproximadamente $82 \mathrm{pb}$ (Figura 1A). De estas muestras positivas, un $29 \%$ (9/31) no son productos con base en maíz como ingrediente primario. Un escenario similar se observó en el tamizaje del terminador $t$-Nos, donde en un $72 \%$
(26/36) de las muestras analizadas se obtuvo bandas con un peso molecular de 84 pb (Cuadro 2) (Figura 1A). Cabe destacar que las muestras M-18, M-20, M-21, M-28 y M-33 no presentaron resultados positivos para $t$-Nos, pero si para la región $35 \mathrm{~S}$. Lo anterior puede deberse a que la muestra presenta eventos transgénicos que no poseen el terminador $t$-Nos en su construcción (p.ej. Mon810 en la muestra M-33), o a una dificultad en la detección de esta secuencia debido al alto grado de procesamiento de los alimentos que podría degradar el ADN y provocar que las trazas del transgén no estén intactas en los ácidos nucleicos totales. Investigaciones similares han demostrado la presencia de alimentos con niveles detectables de secuencias transgénicas en diversos puntos de venta en Costa Rica, de un total de 16 productos analizados, entre tortillas tostadas 
de maíz y harina de maíz, el 50\% de estos resultaron fueron positivos para la región $t$-Nos, sin embargo, se presentaron problemas para amplificar la región $35 S$ (Jiménez 2003). De manera similar, en Turquía se reportó que un 78\% de 19 alimentos para animales y más del $10 \%$ de 56 alimentos procesados analizados contenían soya GM basándose en la detección del promotor $35 \mathrm{~S}$ y el terminador $t$-Nos (Turkec et al. 2015 y Turkec et al. 2016). Reportes en Portugal evidenciaron que un $30 \%$ de las 105 muestras de alimentos procesados a base de maíz y analizadas por PCR, fueron positivas para el promotor $35 S$ y $10 \%$ para el terminador $t$-Nos (Fernández et al. 2014), mientras que en Irán, el 20\% de las 25 muestras, analizadas para el promotor $35 \mathrm{~S}$, de alimentos procesados a base de maíz, fueron positivas (Rabiei et al. 2013). En el continente americano, Fernández et al. (2012) realizaron análisis de transgénesis a 20 harinas de maíz de venta en el mercado uruguayo mediante la amplificación por PCR de punto final de la región $35 S$, que generaron resultados positivos en 18 de las 20 muestras analizadas. Por último, De Faria (2005), reporta que, en Costa Rica, 33 muestras analizadas por bandas de detección de flujo lateral (detección cualitativa de proteína transgénica) y PCR, entre granos y semillas muestreadas en el puerto de Moín / Caldera y ventas de semillas en la capital costarricense, mostraron que un $48 \%$ del total muestreado presentaron resultados positivos para maíz Bt11 y para maíz/soya transgénica resistente a glifosato. Para los ensayos moleculares para eventos transgénicos específicos de maíz, predominó el evento MON810 presente en el 58\% $(21 / 36)$ de las muestras analizadas, en las cuales se observó una banda de 113 pb aproximadamente (Figura 1B), la cual concuerda con el amplicón obtenido en el estudio de Takabatake et al. (2013). Por otra parte, se determinó que un 46\% (14/30) de los alimentos analizados presenta secuencias del evento NK603 (con un amplicón de 108 pb (Figura 1B); mientras que un $41 \%$ (15/36) de las muestras amplificó para Bt11 (70pb) y únicamente el $26 \%(8 / 30)$ amplificó para secuencias del evento GA21 (112 pb) (Figura 1 y Cuadro 2). A nivel internacional, existen reportes de países como Corea del Sur donde un 25\% de 74 diferentes alimentos procesados a base de maíz contenían uno o más eventos específicos de maíz, entre ellos el MON810, el GA21 y el NK603 (Kim et al. 2014). De manera similar, Alcochete y Daniel (2011) realizaron un estudio para detectar eventos transgénicos en Angola mediante cebadores para identificar la región del promotor $35 \mathrm{~S}$, además de eventos específicos como MON810, Bt11 y Bt176, de las 60 muestras analizadas, 24 fueron detectadas como transgénicas. La técnica molecular de PCR punto final posee un grado de sensibilidad de 0,1\% en la detección de OGM (Arleo 2015). Este método ha sido empleado en otras investigaciones como lo indica Flores et al. (2007) y Fernández et al. (2012), los cuales han detectado la presencia de secuencias derivadas de OGM en alimentos comerciales. Sin embargo, es recomendable que las muestras sean analizadas mediante PCR en tiempo real, esto para determinar los porcentajes de OGM que contienen cada una de ellas. En ese sentido, a nivel internacional, la técnica molecular validada por el JRC para la detección cualitativa y cuantitativa de OGMs, es el PCR en tiempo real (qPCR), la cual posee un grado de sensibilidad del $0,01 \%$ en la detección de secuencias derivadas de OGM, y a partir de esta técnica se logró reducir los resultados falsos negativos que podría surgir en alimentos procesados que posean una baja proporción de material transgénico. Algunas de las muestras analizadas resultaron ser positivas para más de un evento específico de maíz, un total de 33 muestras fueron analizadas para la detección de eventos múltiples, el 39\% (13/33) presentó un único evento transgénico, el $15 \%(5 / 33)$ presentó 2 eventos transgénicos, en el 18\% (6/33) se observó la presencia de 3 eventos y el 12\% (4/33) manifestó 4 eventos transgénicos (Cuadro 2). Lo anterior podría indicar la presencia de los llamados eventos transgénicos apilados, tales como los eventos 59122 x MON810 x NK603, GA21 x MON810 o Bt11 x GA-21 (ISAAA 2016), así como el uso de lotes de granos de maíz con diferentes plantaciones de origen (y/o diferente identidad 
transgénica), que son utilizadas para la fabricación del producto alimenticio. Según ChaparroGiraldo (2011), las primeras variedades de OGM contenían únicamente el transgén de interés, sin embargo, los eventos actuales pueden contener más de una construcción transgénica. Por otra parte, en las muestras M-09, M-21 y M-31, no se logró detectar ninguno de los eventos específicos analizados, a pesar de ser positivo para $35 S y$ $t$-Nos, por lo tanto, es necesario realizar pruebas con otros cebadores específicos para otros eventos transgénicos en maíz. Lo anterior se debe a que en el mercado internacional existen 142 eventos de maíz y 29 de soya aprobados para consumo humano, así como 137 de maíz y 29 de soya aprobados para alimentación de animales (ISAAA 2016) y la mayoría presenta en su arquitectura estas secuencias promotoras y terminadoras (Barbau-Piednoir et al. 2010 y Holden et al. 2010). Por otra parte, en el caso específico de la muestra M-1, se detectó la presencia de todos los eventos específicos buscados (GA21, NK603, Bt11, Mon810). Dicha muestra fue producida en El Salvador; país que firmó en el año 2000 un tratado de libre comercio con Estados Unidos, uno de los principales países productores de OGM a nivel mundial. Otros estudios han confirmado mediante ensayos moleculares que existen alimentos modificados genéticamente en El Salvador (Escalante 2008, Orantes et al. 2015). Así mismo se ha determinado la presencia de trazas de transgénicos en las tortillas tostadas de maíz, la harina de maíz, cereal azucarado y tamal asado, los cuales son productos producidos en Costa Rica, según se indica en su etiqueta. Cabe destacar que la producción de maíz es escasa en el país y tanto El Salvador como Costa Rica encabezan la lista de los países Centroamericanos con el mayor índice de importación de maíz, principalmente para la producción de alimentos a base de maíz blanco. Para el período comprendido entre el 2007-2011, Costa Rica se encuentra entre los 25 principales importadores de maíz a nivel mundial (Rivera 2014). Según datos recopilados por el Área de Servicios de Información Agroalimentaria (ASIA) del Consejo Nacional de
Producción de Costa Rica, en el 2015 se importaron 32866 toneladas métricas de maíz blanco, de las cuales el 93\% procede de Estados Unidos de América, y durante el 2014 se importaron 673 636 toneladas métricas de maíz amarillo (Sistema de Información de mercados agroalimentarios, 2016). En cuanto al evento específico de soya GTS 40-3-2 (35soy/CTP4), el 30\% (4/13) del total de muestras analizadas para este evento fueron positivas, detectándose un amplicón esperado de aproximadamente $74 \mathrm{pb}$, sin embargo, $12 / 13(92 \%)$ de las muestras presentaron resultados positivos para el gen de la lectina de soya (Figura 1B y Cuadro 2), aspecto que indicó que la mayoría de muestras analizadas y elaboradas con derivados de soya, no presentaban el evento GTS 40-3-2. En Costa Rica el cultivo de soya es reducido, por lo cual debe ser importado, problema similar al que ocurre en Ecuador donde la soya es un cultivo cuya producción nacional no es suficiente para suplir la demanda interna. Por esta razón, se recurre a la importación de soya en grano para consumo desde países donde el uso de soya transgénica ha sido aprobado (De Lourdes et al. 2013).

En cuanto a los análisis por secuenciación de ADN, las observaciones de identidad mediante la herramienta BLASTn de las secuencias genéticas derivadas de los productos de PCR obtenidos de la detección molecular de $t$-Nos y de los eventos MON810, GA-21, NK603 y GTS 40-3-2, mostraron una alta similitud con secuencias depositadas en la base de datos del NCBI. El producto génico obtenido del alimento M-55 con el cebador $t$-Nos mostró una identidad del 93\% con un plásmido de referencia para detección de OGM que contenía el terminador NOS (número de accesión $J X 434028$ ). El fragmento secuenciado del amplicón MON810 (alimento M-53) presenta una identidad del $95 \%$ con el vector de expresión pMON99036 (número de accesión $J N 400388$ ). Por otra parte, el amplicón GA-21 generado del alimento M-01, muestra 98\% de identidad con la accesión $H Q 161054$, la cual posee un fragmento de la secuencia transgénica del gen cry1 Ab/c. La secuencia NK603 obtenida 
del alimento M-43 presenta una identidad del 98\% con un fragmento del genoma cloroplástico de una línea B37T de maíz (número de accesión KP966117). Finalmente, la secuencia obtenida del alimento M-45 para el evento GTS 40-3-2 posee un $100 \%$ de identidad con una secuencia que posee información del precursor EPSPS cloroplástico (número de accesión JF499829). Lo anterior confirma, que los amplicones obtenidos en este estudio, entre los pesos moleculares de 70 a $113 \mathrm{pb}$, pertenecen a secuencias de ADN utilizadas en cultivos genéticamente modificados. Este estudio permitió identificar la presencia de secuencias transgénicas derivadas de organismos genéticamente modificados en más del $60 \%$ de las muestras analizadas, lo que evidenció que muchos de los alimentos de consumo diario en los hogares costarricenses con base en maíz y soya, disponibles en supermercados nacionales, contienen niveles detectables de secuencias derivadas de OGM. El evento específico de mayor predominancia en las muestras de maíz analizadas fue el MON810, presente en más del 50\% de éstas, lo que indica que las muestras positivas para este evento contienen la modificación de un gen que codifica para la proteína Cry1Ab procedente de Bacillus thuringiensis. Por otro lado, de las muestras analizadas para la presencia de secuencias de ADN de soya transgénica GTS 40-3-2, únicamente el 30\% mostró resultados positivos, lo que indica que la mayor parte de los productos examinados no presentaban trazas de este evento. Aunque los alimentos derivados de OGM disponibles en el mercado internacional y autorizados para consumo humano, no presentaran un riesgo para la salud (Departamento de Agricultura de los Estados Unidos de América 2016, Nicolia et al. 2014, Organización Mundial de la Salud 2014, Snell et al. 2012, Zhang et al. 2014); los resultados de la investigación evidencian la responsabilidad del gobierno en la formulación de políticas y la toma de decisiones con respecto a la importancia y la viabilidad del etiquetado de los alimentos derivados de OGM disponibles en el mercado nacional, según las sugerencias y directrices de la Organización de las Naciones Unidas para la Agricultura y la Alimentación (Organización de las Naciones Unidas para la Agricultura y la Alimentación 2011).

\section{AGRADECIMIENTOS}

A la Dirección de la Escuela de Ciencias Biológicas de la Universidad Nacional (ECBUNA), por su apoyo y cooperación en esta iniciativa de investigación. A Jaime E. García G, Catedrático de la UCR- UNED, por su revisión a este manuscrito.

\section{LITERATURA CITADA}

Ahmed, FE. 2002. Detection of genetically modified organisms in foods. Trends in Biotechnology 20(5):215-223.

Alcochete, A; Daniel, I. 2011. Detection of transgenic maize (Zea mays L.) in Angola. Ciencia y Tecnología 1:719 .

Altschul, SF; Gish, W; Miller, W; Myers; EW; Lipman, DJ. 1990. Basic local alignment search tool. Journal of Molecular Biology 21:403-410.

Álvarez-Guevara, MH; Gil-Moreno, LG; Gómez-Rodríguez, JA; Huete-Pérez, JA. 2012. Overview of genetically modified crops and their relevance for Nicaragua. Encuentro 93:63-77.

Arleo, M. 2015. Detección y cuantificación de organismos genéticamente modificados en cultivos de maíz y alimentos derivados, mediante análisis molecular. Tesis M.Sc. Montevideo, Uruguay, Universidad de la República, Montevideo. 170 p.

Barbau-Piednoir, E; Lievens, A; Mbongolo-Mbella, G; Roosens, N; Sneyers, M; Leunda-Casi, A; van den Bulcke, M. 2010. SYBR ${ }^{\circledR}$ Green qPCR screening methods for the presence of " $35 \mathrm{~S}$ promoter" and "NOS terminator" elements in food and feed products. European Food Research and Technology 230(3):383-393.

Bonfini, L; van den Bulcke, MH; Mazzara, M; Ben, E; Patak, A. 2012. GMOMETHODS: The European Union database of reference methods for GMO analysis. Journal of AOAC International 95(6):1713-1719.

Chaparro-Giraldo, A. 2011. Cultivos transgénicos: entre los riesgos biológicos y los beneficios ambientales y económicos. Acta Biológica Colombiana 16(3):231252.

Claver, L. 2013. El cultivo comercial de soya transgénica (evento mon-04032-6): riesgo para la apicultura mexicana. Tesis M.Sc. Québec, Canadá, L’Université de Sherbrooke. 116 p. 
De Faria, F. 2005. Granos y semillas transgénicos en cadena alimentaria: Costa Rica. Ambientico 137:19-21.

De Lourdes-Torres, M; Arahana, V. 2013. Estandarización de un protocolo para detección de OGMs: evaluación de la presencia de OGMs en granos de soya colectados en diferentes centros de acopio de Ecuador. Avances 5(1):B40-B48.

Departamento de Agricultura de los Estados Unidos de América. 2016. Biotechnology Frequently Asked Questions (FAQs) (en línea). Consultado 30 mar. 2016. Disponible en http://www.usda.gov/wps/ portal/usda/usdahome?navid=AGRICULTURE\&co ntentid=BiotechnologyFAQs.xml

Doyle, JJ; Doyle, JL. 1987. A rapid DNA isolation procedure for small quantities of fresh leaf tissue. Phytochemical Bulletin 19:11-15.

Escalante-Ramírez, SG. 2008. Propuesta de norma de etiquetado de los alimentos procesados provenientes de organismos genéticamente modificados (OGM) en El Salvador. Tesis Lic. San Salvador, El Salvador, Universidad de El Salvador, 208 p.

Fernández, M; da Silva, A; Martínez, C. 2012. Análisis de transgénesis mediante PCR de 20 harinas de maíz que se encuentran a la venta en el mercado uruguayo. Revista Iberoamericana de Tecnología Postcosecha 13(1):92-104.

Fernández, TJ; Amaral, JS; Oliveira, MB; Mafra, I. 2014. A survey on genetically modified maize in foods commercialised in Portugal. Food Control 35(1):338344.

Flores YA; Herrera, RR; Aguilar, CN; Carlos, J; Esquivel, C. 2007. Nuevos métodos para la detección de residuos de organismos genéticamente modificados en alimentos basados en el ADN. BioTecnología 11(2):28-36.

Franco-Ortíz, M; Lizama-Argueta, EJ; Panameño-Moreno, JA. 2014. Repercusiones económicas de los Tratados de Libre Comercio suscritos por El Salvador en la industria alimentaria: 2000-2011. Tesis Lic. San Salvador, El Salvador, Universidad de El Salvador. $50 \mathrm{p}$.

Gallagher, SR. 2001. Quantitation of DNA and RNA with absorption and fluorescence spectroscopy. Current Protocols in Cell Biology 7 supl. 53:3D:A.3D.1A.3D8

García, JE. 2007. Cultivos genéticamente modificados: las promesas y las buenas intenciones no bastan. Revista Biología Tropical 55(2):347-364

González, MA. 2014. Marco jurídico del derecho a la información en la utilización de organismos genéticamente modificados en el sector agrícola: análisis comparativo de México y Canadá. Tesis Lic. Ciudad de México, México, Universidad Nacional Autónoma de México. 171 p.

Holden, MJ; Levine, M; Scholdberg, T; Haynes, RJ; Jenkins, GR. 2010. The use of $35 \mathrm{~S}$ and Tnos expression elements in the measurement of genetically engineered plant materials. Analytical and Bioanalytical Chemistry 396(6):2175-2187.

Holst-Jensen, A; Ronning, SB; Loveseth, A; Berdal, KG. 2003. PCR technology for screening and quantification of genetically modified organisms (GMOs). Analytical and Bioanalytical Chemistry 375(8):985-993.

Hurst, CD; Knight, A; Bruce, IJ. 1999. PCR detection of genetically modified soya and maize in foodstuffs. Molecular Breeding 5(6):579-586.

ISAAA (International Service for the Acquisition of AgriBiotech Applications). 2016. GM Approval Database. Consultado 24 mar. 2016. Disponible en http://www. isaaa.org/gmapprovaldatabase

James, C. 2015. Global Status of Commercialized Biotech/ GM Crops: 2015. International Service for the Acquisition of Agri-biotech Applications (ISAAA) Brief $N^{\circ}$. 51. New York, Estados Unidos, Ithaca.

Jiménez, PM. 2003. (Informe de Práctica de Especialidad). Centro de Investigación en Biotecnología (CIB). Detección de alimentos y cultivos modificados genéticamente. Cartago, Costa Rica. 91 p.

Johnson, M; Zaretskaya, I; Raytselis, Y; Merezhuk, Y; McGinnis, S; Madden, T.L. 2008. NCBI BLAST: a better web interface. Nucleic Acids Research 36 (suppl_2): W5-W9.

Kim, JH; Zhang, D; Kim HY. 2014. Detection of sixteen genetically modified maize events in processed foods using four event-specific pentaplex PCR systems. Food Control 35(1):345-353.

Landaverry, G. 2014. Debilidad regulatoria de los transgénicos en Guatemala; alternativas, riesgos, amenazas e intereses. Revista Iberoamericana de Economía Ecológica 22:35-51.

Ley de Biodiversidad $N^{\circ}$. 7788. 1998. Diario Oficial La Gaceta. Costa Rica. 27 may. 1998.

Margarit, E; Reggiardo, MI; Vallejos, RH; Permingeat, HR. 2006. Detection of BT transgenic maize in foodstuffs. Food Research International 39(2):250255.

Ministerio de Agricultura y Ganadería (MAG). 2016a. Centro de Intercambio de Información sobre Seguridad de la Biotecnología. Biosafety Cleanring House (BCH). San José, Costa Rica (en línea). Unidad de Organismos Genéticamente Modificados (UOGM), Servicio Fitosanitario del Estado. MAG, Costa Rica. Consultado 17 abr. 2016 Disponible en http://www. bch.go.cr/Portafolio/Datos\%20estadisticos $\% 20$ desde\%201991\%20a\%20enero\%202016\%20.pdf

Ministerio de Agricultura y Ganadería (MAG). 2016b. Orientación y guía para el cumplimiento del Reglamento de Auditorías en Bioseguridad Agrícola $N^{\circ}$. 32486- MAG y normativa relacionada (en línea). San José, Costa Rica. Unidad de Organismos Genéticamente Modificados (UOGM), Servicio Fitosanitario del Estado. MAG, Costa 
Rica. Consultado 17 abr. 2016. Disponible en http:// www.bch.go.cr/Portafolio/Publicaciones/Auditoriasvf-divulgaci\%C3\%B3n.pdf

Morales-Estupiñán, C. 2001. Las nuevas fronteras tecnológicas: promesas, desafíos y amenazas de los transgénicos. Santiago, Chile, CEPAL. 73 p.

Nicolia, A; Manzo, A; Veronesi, F; Rosellini, D. 2014. An overview of the last 10 years of genetically engineered crop safety research. Critical Reviews in Biotechnology 34(1):77-88.

Orantes, EA; Cañas, JI; Martínez, L; Gómez, OF; ZúnigaGonzález, CA. 2015. Análisis de la agenda pública y privada de la Bioeconomía en Centroamérica y el Caribe: Estudios de Caso de El Salvador, Honduras, Cuba y Nicaragua. Revista Iberoamericana de Bioeconomía y Cambio Climático 1(1):241-284.

Organización de las Naciones Unidas para la Agricultura y la Alimentación. 2011. Frequently Asked Questions about FAO and Agricultural Biotechnology (en línea). Consultado 30 mar. 2016. Disponible en http://www.fao.org/fileadmin/user_upload/biotech/ docs/faqsen.pdf

Organización Mundial de la Salud. 2014. Frequently asked questions on genetically modified foods (en línea). Consultado 30 mar 2016. Disponible en http://www. who.int/foodsafety/areas_work/foodtechnology/ Frequently_asked_questions_on_gm_foods. pdf?ua $=1$

Pacheco-Rodríguez, F; García-González, JE. 2014. Situación de los cultivos transgénicos en Costa Rica. Acta Académica 54:29-60.

Pauli, U; Liniger, M; Zimmermann, A; Schrott, M; Schouwey, B. 2000. Extraction and amplification of DNA from 55 foodstuffs. Mitteilungen aus Lebensmitteluntersuchung und Hygiene 91(5):491501.

Querci, M; Foti, N; Bogni, A; Kluga, L; Broll, H; van den Eede, G. 2009. Real-time PCR-based ready-to-use multi-target analytical system for GMO detection. Food Analytical Methods 2(4):325-336.

Rabiei,M; Mehdizadeh,M; Rastegar,H; Vahidi,H; Alebouyeh, M. 2013. Detection of genetically modified maize in processed foods sold commercially in Iran by qualitative PCR. Iranian Journal of Pharmaceutical Research 12(1):25.

Rivera, R. 2014. Las cadenas de valor del maíz blanco y el frijol en Centroamérica: actores, problemas y acciones para su competitividad. Instituto Interamericano de Cooperación para la Agricultura (IICA), Red SICTA, Cooperación Suiza en América Central. San José, Costa Rica, IICA. 17 p.
Schaper, M; Parada, S. 2001. Organismos genéticamente modificados: su impacto socioeconómico en la agricultura de los países de la Comunidad Andina, Mercosur y Chile. División de Medio Ambiente y Asentamientos Humanos Comisión Económica para América Latina y el Caribe (CEPAL), en Santiago de Chile Naciones Unidas, CEPAL.

Sistema de Información de Mercados Agroalimentarios. 2016. Costa Rica. Volumen de las importaciones de maíz blanco según mes, período 1980-2015 (en línea). Consultado 30 mar. 2016. Disponible en http://www.simacr.go.cr/index.php/importacionesde-maiz

Snell, C; Bernheim, A; Bergé, JB; Kuntz, M; Pascal, G; Paris, A; Ricroch, AE. 2012. Assessment of the health impact of GM plant diets in long-term and multigenerational animal feeding trials: a literature review. Food and Chemical Toxicology 50(3):11341148.

Takabatake, R; Takashima, K; Kurashima, T; Mano, J; Furui, S; Kitta, K; Koiwa, T; Akiyama, H; Teshima, R; Futo, S; Minegishi, Y. 2013. Interlaboratory study of qualitative PCR methods for genetically modified maize events MON810, BT11, GA21, and CaMV p35s. Journal of AOAC International 96(2):346-352.

Turkec, A; Kazan, H; Baykut, A; Lucas, SJ. 2015. Evalution of DNA extraction methods in order to monitor genetically modified materials in soy foodstuffs and feeds commercialized in Turkey by multiplex real-time PCR. Journal of the Science of Food and Agriculture 95(2):386-392.

Turkec, A; Lucas, SJ; Karlik, E. 2016. Monitoring the prevalence of genetically modified (GM) soybean in Turkish food and feed products. Food Control (59):766-772.

van den Eede, G; Bonfini, L; Cengia, L; Iannini, C; Kluga, L; Mazzara, M. 2010. Compendium of reference methods for GMO analyses (en línea). Publications Office of the European Union. Consultado 30 mar. 2016. Disponible en: http://publications.jrc. ec.europa.eu/repository/handle/111111111/15068

Zhang, M; Zhuo, Q; Tian, Y; Piao, J; Yang, X. 2014. Longterm toxicity study on transgenic rice with CrylAc and sck genes. Food and Chemical Toxicology 63:76-83.

Zimmermann, A; Lüthy, J; Pauli, U. 1998. Quantitative and qualitative evaluation of nine different extraction methods for nucleic acids on soya bean food samples. Zeitschrift für Lebensmitteluntersuchung undForschung A 207(2):81-90. 